\title{
QUALIDADE DA ÁGUA NO RIO MUMBUCA DE LAMBARI-MG
}

\author{
Ana Paula Silva da Cunha OLIVEIRA ${ }^{1}$
}

Sandra Aparecida NOGUEIRA ${ }^{2}$

Maurício Cezar Resende LEITE JUNIOR ${ }^{3}$

Alexandre Mendonça TOURINO ${ }^{4}$

\begin{abstract}
${ }^{1}$ Graduando do curso de Engenharia Ambiental da Universidade Vale do Rio Verde (UninCor). paula_anacax@hotmail.com

${ }^{2}$ Graduando do curso de Engenharia Ambiental da Universidade Vale do Rio Verde (UninCor). sandrinhalambari@hotmail.com

3Professor Tempo integral na Universidade Vale do Rio Verde (UninCor), Doutor em Recursos Hídricos em Sistemas Agrícolas. mauricio_cezar_leite@yahoo.com.br

${ }^{4}$ Professor Tempo integral na Universidade Vale do Rio Verde (UninCor), Doutor em Microbiologia e Bioquímica. alexandretourino@gmail.com
\end{abstract}

Recebido em: 02/03/2016 - Aprovado em: 18/07/2016 - Disponibilizado em: 18/12/2016

\section{RESUMO:}

O impacto humano sobre os recursos hídricos aumenta junto com o crescimento da população, com o início da industrialização a poluição hídrica aumentou muito, pois o consumo de água ficou maior. O objetivo é descrever as melhorias para a população em geral com o aumento na oferta de saneamento básico, identificando os principais problemas de saneamento básico da população e suas possíveis soluções, foi determinada a qualidade da água no Rio Mumbuca antes e após passagem pela cidade de Lambari/MG para verificar se o município de Lambari interfere na qualidade da mesma. O universo da pesquisa foi concentrado na distribuição de água e seu tratamento no município de Lambari-MG no setor de saneamento básico buscando-se um panorama da situação do tratamento da água do rio Mumbuca que abastece a população. Foram realizadas duas coletas em cada ponto no período matutino e vespertino baseados nos seguintes critérios: Ponto 1: Amostra coletada na nascente do Rio Mumbuca; Ponto 2: amostra coletada depois da passagem de suas águas pelo centro urbano do município. As amostras dos pontos 1 e 2 foram comparadas, identificando se há alteração na qualidade da água do Rio. Os parâmetros analisados foram: Coliformes Totais e Fecais; Cor; Dureza total; Sólidos Dissolvidos,em Suspensão,Sedimentáveis,Totais;Turbidez ; DBO; DQO; pH; Em resultados preliminares foi verificado que ocorreu interferência na qualidade da água do rio Mumbuca após sua passagem pelo município de Lambari/MG, podendo esses resultados serem confirmados após o recebimento de todas as análises de água.

Palavras-Chave: Impacto ambiental; poluição hídrica; saneamento.

\section{WATER QUALITY IN RIO MUMBUCA OF LAMBARI-MG}

\begin{abstract}
:
The human impact on water resources increases with population growth, with the onset of industrialization water pollution has increased manifold because water consumption was higher. The aim is to describe the improvements to the general population with increased sanitation provision, identifying major sanitation problems of the population and possible solutions was determined the water quality in the Rio Mumbuca before and after passage by the City of tetra / MG to check whether the municipality of tetra interferes with the quality of it. The universe of the research was focused on the distribution of water and its treatment in Lambari-MG municipality in the basic sanitation sector is seeking an overview of Mumbuca River Water Treatment situation that supplies the population. There were two collections at each point in the morning and evening based on the following criteria: Point 1: Sample collected at the source of River Mumbuca; Point 2: sample collected after the passage of the water by the urban center of the city. . Samples of items 1 and 2 were compared, identifying if there is change in water quality of the River The parameters analyzed were: Total Coliform and Faecal; Color; Total hardness; Dissolved solids in suspension, Sedimentable, Total; Turbidity; BOD; $\mathrm{COD}$; $\mathrm{pH}$; In preliminary results it was found that there was interference in the Mumbuca river water quality after its passage by the municipality of Lambari / MG, can these results be confirmed upon receipt of all analyzes of water.
\end{abstract}

Keywords: Environmental impact; water pollution; basic sanitation. 


\section{INTRODUÇÃO}

A água é rara na superfície dos planetas em forma líquida, os oceanos contêm 97\% da água superficial no planeta, as geleiras e calotas polares têm 2,4\%, rios, lagos e lagoas abrigam 0,6\%, a água é limitada, mas não insuficiente. No ciclo hidrológico o líquido é depurado e redistribuído atendendo as necessidades da terra, esse processo ocorre há 4,6 bilhões de anos.

Os problemas efetivamente apareceram quando pela ação do homem, a água passou a ser devolvida para o meio ambiente com sua qualidade modificada, através de contaminação por elementos orgânicos e inorgânicos na forma de efluentes e lodos. Lembrando que toda a preocupação com a poluição e a crescente escassez da água afeta principalmente os seres humanos.

O impacto humano sobre os recursos hídricos aumenta junto com o crescimento da população, com o início da industrialização a poluição hídrica aumentou muito, pois o consumo de água ficou maior.

As aglomerações humanas, aliadas á expansão industrial, começaram a despertar a preocupação da humanidade, levando á adoção de medidas preventivas para minimizar, preservar ou corrigir possíveis agravos ao meio ambiente e a saúde.

Assim, surge o saneamento e a saúde pública, ciências ou áreas disciplinares que utilizando conceitos e definições básicas de outros ramos do conhecimento humano, procuram indicar e trazer soluções a problemas causados em diversas vezes pela própria ação do homem no intuito de usufruir a natureza.

Toda a contaminação a que é submetida, a água não desaparecerá, mas poderá se tornar cada vez mais poluída e misturada a resíduos sólidos. Este processo fará com que sua limpeza para usos mais nobres se tornará gradualmente mais cara e sua concentração em lagos, rios e no subsolo poderá mudar.

O Brasil alcançou progresso substancial na cobertura de serviços de saneamento nos anos de 1970, 1980 e 1990, sendo grande parte desse esforço fruto do Plano Nacional de Saneamento (PLANASA). Em áreas urbanas, o acesso a água potável cresceu de 50\% em 1968 para 97\% em 2010.

Apesar do Brasil apresentar índices mais altos de abastecimento de agua do que outros países vizinhos ao nosso, no que se refere ao esgotamento a cobertura é menor do que a de vários países vizinhos. $81 \%$ da população do país tem abastecimento de água tratada. Os 37 milhões que não são atendidos em suas necessidades básicas de água habitam principalmente a região norte, nordeste e o centro-oeste. Além de deixar de suprir parte considerável da população com água tratada, em média 38\% do volume de água tratada são perdidos no sistema de distribuição. Lembrando que somente $47 \%$ do esgoto sanitário são coletados e apenas $38 \%$ deste 
volume coletado é tratado, o que quer dizer que menos $18 \%$ do volume total do esgoto gerado no Brasil são tratados.

Segundo dados do ministério da saúde, apenas $67 \%$ das cidades estão preparados para fiscalizar e avaliar a qualidade da água que sua população consome assim não se sabe a situação da água nas fontes de fornecimento lagos, rios, nascentes no tratamento e nem no produto final, distribuído aos consumidores.

\section{MATERIAIS E MÉTODO}

Lambari é um município brasileiro situado no sul do estado de Minas Gerais. Em 2014 sua população foi estimada pelo IBGE em 20.564 habitantes. É uma estância hidromineral e faz parte do famoso Circuito das Águas. A cidade é abastecida pelo Rio Mumbuca, que é o principal e o mais extenso do município, banha e abastece a cidade. Nasce no bairro Mantiva, passa pelos bairros Mumbuca e Jacu, recebe águas dos córregos: Barreiro, Lobos, Cadeia e do Lago Guanabara. Passa pelo bairro Serrote e deságua no rio Lambari.
O universo da pesquisa foi concentrado na distribuição de água e seu tratamento no município de Lambari-MG no setor de saneamento básico buscando-se um panorama da situação do tratamento da água do rio Mumbuca que abastece a população.

Foram realizadas duas coletas em cada ponto no período matutino e vespertino baseados nos seguintes critérios (Figura 1).

As amostras do ponto 1 (a montante), foram coletadas no dia 06/10/2015 as 07:15 horas da manhã. As amostras foram coletadas em duas garrafas pets de $500 \mathrm{ml}$, após serem lavadas três vezes com a própria água do ponto de coleta para criar ambiente. Após terminar a coleta das amostras, foram colocadas numa caixa térmica com gelo, uma das amostras foi enviada ao Laboratório de Análises de Água da Universidade Federal de Lavras e a outra para o Laboratório de Análises de Água da Universidade Vale do Rio Verde. Este mesmo procedimento foi realizado na parte da tarde às $16 \mathrm{~h} 30 \mathrm{~min}$.

Figura 1: Amostra coletada na nascente do Rio Mumbuca (imagem da esquerda) amostra coletada depois da passagem de suas águas pelo centro urbano do município (imagem da direita).

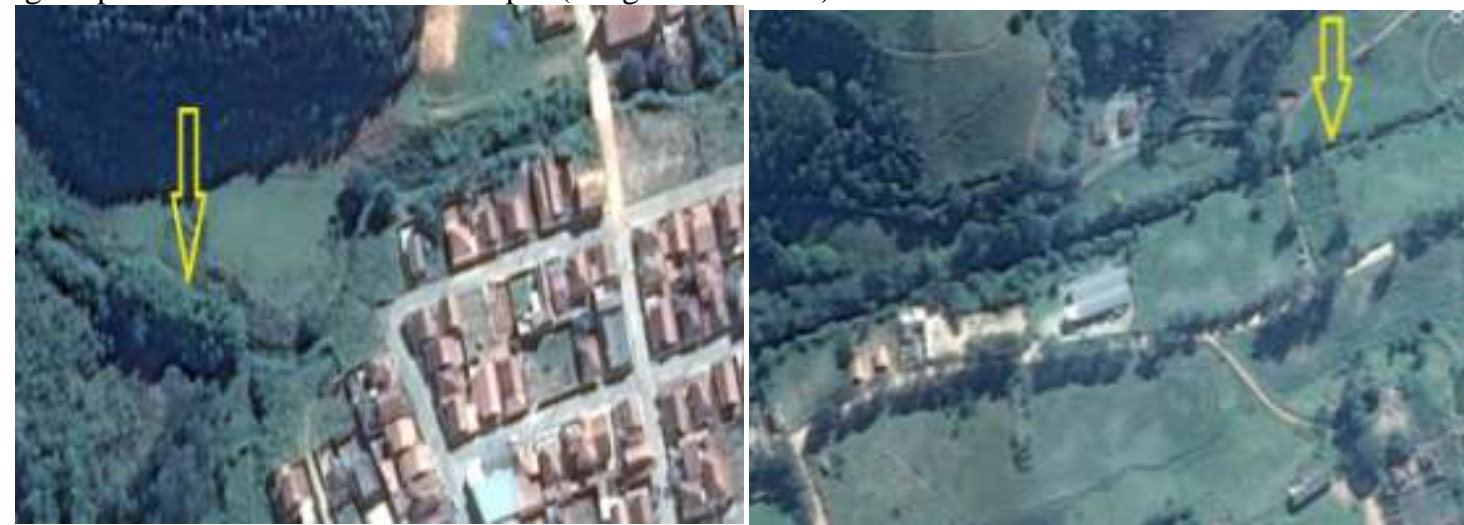

Fonte: Google Earth, 2016. 
As amostras do ponto 2 (a jusante), foram coletadas no dia 06/10/2015 as 08:00 horas da manhã. As amostras foram coletadas da água jusante do Rio Mumbuca, foram utilizados baldes e cordas para arremessá-los dentro do rio para a coleta da água, as amostras foram colocadas em duas garrafas pets de $500 \mathrm{ml}$, após terminar a coleta das amostras, foram colocadas numa caixa térmica com gelo e enviadas ao laboratório de Análises de Água da Universidade Federal de Lavras e a outra para o Laboratório de Análises de Água da Universidade Vale do Rio Verde. Este processo foi realizado na parte da tarde as 17:00 horas. Todas as amostras foram identificadas.

No Laboratório de Análises de Água da UninCor, foram realizadas as análises de Coliformes Fecais, seguindo a seguinte metodologia:

Para a realização das análises foram utilizados 20 tubos de salina, 80 tubos de lauril com duhram, 20 pipetas de $1 \mathrm{ml} / 2 \mathrm{ml} /$ $5 \mathrm{ml}$.

Para os 20 tubos de salina foram utilizados 100 gramas da composição de salina em $400 \mathrm{ml}$ de água, obtendo-se 80 gramas do meio.

Foram distribuídos $1 \mathrm{ml}$ de salina em cada tubo $\left(10^{-1} ; 10^{-2} ; 10^{-3} ; 10^{-4}\right.$ e $\left.10^{-5}\right)$ nos primeiros 40 tubos das águas à montante $\mathrm{e}$ jusante. Nos tubos de lauril foram colocadas 35,6 gramas da composição para $1000 \mathrm{ml} \mathrm{em}$ $800 \mathrm{ml}$ de água destilada, obteve-se 28,48 gramas do meio. Foram distribuídos 53,1\% do verde brilhante para $1000 \mathrm{ml} \mathrm{em} 800 \mathrm{ml} \mathrm{de}$ água destilada, resultando em 42,48g do meio.

No Laboratório de Análises de Água da UFLA, foram realizas as seguintes análises:

a) Cor

b) $\mathrm{DBO}$

c) $\mathrm{DQO}$

d) Dureza Total

e) $\mathrm{pH}$

f) Sólidos Dissolvidos

g) Sólidos Sedimentáveis

h) Sólidos em Suspensão

i) Sólidos Totais

j) Turbidez

k) Coliformes Totais e Fecais

As amostras dos pontos 1 e 2 serão comparadas, identificando se há alteração na qualidade da água do Rio Mumbuca.

\section{RESULTADOS E DISCUSSÃO}

Nesse tópico serão apresentados todos os resultados da pesquisa, considerando as condições climáticas do local e todas as análises realizadas nas águas do rio Mumbuca.

No dia 06/10/2015 foram realizadas coletas da água da montante e jusante do rio Mumbuca de Lambari para verificar a qualidade da água antes da passagem pela cidade e após a passagem de suas águas pelo centro urbano do município. 
Observou-se as condições climáticas de alguns parâmetros meteorológicos que podem interferir nos resultados, como a temperatura, umidade e precipitação,neste caso provavelmente a precipitação pode ter interferido na qualidade da água do rio Mumbuca. Os dados climáticos tiveram referência na estação meteorológica de Varginha - MG, visto que, é a estação meteorológica mais próxima aos pontos analisados.

Na Tabela 2 é possível observar a ocorrência de precipitações nos dias 3 e 4 de outubro, que antecederam o dia de coleta das amostras, tais precipitações podem ter carreado matéria orgânica, fezes de animais, sólidos em suspensão e outros fatores que podem interferir na qualidade da água.

Tabela 2: Dados meteorológicos da estação climática de Varginha/MG

\begin{tabular}{llllll}
\hline DIA: & HORA & Temperatura & Umidade(\%) & Radiação & Precipitação \\
\hline \multirow{3}{*}{$03 / 10 / 15$} & (UTC) & (Max/Min) & (Max/Min) & $\left(\mathrm{Kj} / \mathrm{m}^{2}\right)$ & $(\mathrm{mm})$ \\
\cline { 2 - 6 } & $05: 00 \mathrm{hs}$ & $21,9 / 18,8$ & $86 / 62$ & $-3,44$ & 2,4 \\
& $06: 00 \mathrm{hs}$ & $19,0 / 18,2$ & $89 / 84$ & $-3,08$ & 0,4 \\
\hline \multirow{2}{*}{$04 / 10 / 15$} & $11: 00 \mathrm{hs}$ & $19,3 / 18,3$ & $89 / 83$ & 213,8 & 0,2 \\
\hline
\end{tabular}

Fonte: Próprio autor, Três Corações 2016.

Os parâmetros analisados nas amostras 1 e 2 estão apresentados na Tabela 3.

Tabela 3: Parâmetros analisados nas amostras 1 e 2.

\begin{tabular}{lccccc}
\hline \multicolumn{1}{c}{ Parâmetros analisados } & $\begin{array}{c}\text { Amostra1 } \\
\text { (montante) } \\
\text { manhã }\end{array}$ & $\begin{array}{c}\text { Amostra1 } \\
\text { (jusante) } \\
\text { manhã }\end{array}$ & $\begin{array}{c}\text { Amostra 2 } \\
\text { (montante) } \\
\text { tarde }\end{array}$ & $\begin{array}{c}\text { Amostra 2 } \\
\text { (jusante) tarde }\end{array}$ & $\begin{array}{c}\text { Normas } \\
\text { COPAM }\end{array}$ \\
\hline Ph & 6,5 & 6,5 & 6,4 & 6,3 & 6,0 a9,0 \\
DBO(mg/L) & 10 & 8 & 2 & 8 & 60 \\
DQO(mg/L) & 25 & 12 & 31 & 16 & 180 \\
Cor(mgPt/L) & 9,16 & 46,66 & 7,76 & 47,6 & 30 \\
Turbidez(NTU) & 0,82 & 9,55 & 0,66 & 9,78 & 40 \\
Dureza Total(mg/L) & 0 & 36 & 0 & 44 & - \\
Sólidos & 0 & 0 & 0 & 0 & 1 \\
Sedimentáveis(ml/L) & & & & & \\
Sólidos & 37 & 10 & 8 & 3 & 100 \\
Suspensos(mg/L) & 35 & 33 & 50 & 93 & - \\
Sólidos Totais(mg/L) & 80 & 82 & 75 & 97 & 500 \\
Sólidos & $2,5^{*} 10^{-3}$ & $1,1 * 10^{5}$ & $4 * 10^{-1}$ & $1,1 * 10^{5}$ & - \\
Dissolvidos(mg/L) & $4,5^{*} 10^{4}$ & $1,1^{*} 10^{5}$ & - & $1,1 * 10^{5}$ & - \\
Coliformes totais & & & & & \\
Coliformes & & & &
\end{tabular}

Fonte: Próprio autor, Três Corações 2016. 
Os parâmetros pH, DBO, DQO, Cor, Turbidez e sólidos dissolvidos não tiveram diferença entre as amostras tanto na parte da manhã quanto na parte da tarde.

A DBO apresentou uma diminuição na parte da tarde para a parte da manhã,possivelmente pela presença de matéria orgânica e consumo de oxigênio.

A cor teve um aumento significativo na jusante das amostras1e 2 nos períodos da manhã e tarde,pode ter sido ocasionada pela emissão de esgoto, falta de saneamento básico e poluição extrema.

Sólidos suspensos houve um aumento de $78,38 \%$ da montante de manhã para a tarde e de $70 \%$, teve uma ocorrência menos substancial da água jusante de manhã para a tarde, sólidos totais houve uma diferença de $71,82 \%$ da jusante das amostras 1e 2 para a parte da tarde,sólidos dissolvidos diferença de $18,29 \%$ da jusante das amostras 1 e 2 da parte da manhã para a parte da tarde, possivelmente foram obtidas devido a precipitação.

Dureza total teve uma diferença de $22 \%$ da jusante da parte da manhã para a parte da tarde um valor onde podemos classificar a dureza da água como mole,ou seja houve pouca precipitação de acordo com os teores de sais minerias ,de cálcio e magnésio, expressos em mg/L de $\mathrm{CaCO}_{3}$, a água pode ser classificada em: Água mole Até $50 \mathrm{mg} / \mathrm{L}$; Água moderadamente dura de 50 a $150 \mathrm{mg} / \mathrm{L}$; Água dura de 150 a 300 mg/L; Água muito dura Acima de 300 mg/L. (RICHTER e NETO, 1991).

Os coliformes totais da montante 1 mostrou que a água não é potável no período da manhã existe contaminação,no período da tarde,o resultado obtido na montante 2 que a água é praticamente sem contaminação. $\mathrm{Na}$ jusante 1 e 2 nos períodos da manhã e da tarde a água é altamente contaminada.Os coliformes da montante 1deram um baixo nível de contaminação no período da manhã e no período da tarde sem nenhum tipo de contaminação,já na jusante dos pontos 1 e 2 nos dois períodos da manhã e da tarde deram um alto nível de contaminação.

\section{CONCLUSÃO}

Aparentemente depois que a água passou pela cidade a qualidade piorou o único valor fora da norma do COPAM é o da cor, que apresenta uma coloração turva e forte.

Apesar de ter tido uma piora a água ainda é considerada uma água potável por estar dentro das normas do COPAM, e a população interfere na qualidade da água,por falta de saneamento em alguns bairros da cidade e falta de consciência da própria população.

\section{REFERÊNCIAS}

AGÊNCIA NACIONAL DE ÁGUAS (ANA). Caderno de recursos hídricos:

Disponibilidade e demandas de recursos hídricos no Brasil. Ministério do Meio Ambiente. Brasília - DF, 2005 a. 134p. 
BRASIL. Portaria $\mathbf{n}^{0}$ 518, de 25 de março de 2005: Normas de qualidade da água para consumo humano. Ministério da Saúde, Brasília, 2005. 15p.

CONAMA - Conselho Nacional do Meio Ambiente. Resolução n ${ }^{\circ}$ 357/05. Estabelece a classificação das águas doces, salobras e salinas do Território Nacional. Brasília, SEMA, 2015.

INSTITUTO BRASILEIRO DE GEOGRAFIA E ESTATÍSTICA (IBGE). Atlas do saneamento 2005. Disponível em: http://www.ibge.gov.br/home/estatistica/popu lacao/atlassaneamento/index.html $(09 / 06 / 2015)$

LIMA, J. E. F. W; FERREIRA, R. S. A; CHRISTOFIDIS, D. O uso da irrigação no Brasil. In: Estado das águas no Brasil 2009: Perspectivas de gestão e informação de recursos hídricos. SIH/ANEEL/MME; SRH/MMA. 2009, p. 73-82

PÁDUA, V. L.; FERREIRA, A. C. S. Qualidade da água para consumo humano. In: Abastecimento de água para consumo humano. Belo Horizonte: Ed. UFMG, 2006, p. $153-222$

SPERLING, Marcos Von. Introdução à qualidade das águas e ao tratamento de esgotos. $3^{\text {a }}$ Edição. Princípios do tratamento biológico de águas residuárias. Editora da Universidade Federal de Minas Gerais UFMG - Belo Horizonte, 2005.

TUNDISI, J. G.; TUNDISI, T. M. Limnologia. São Paulo: Oficina de Textos, 2008.

TUNDISI, J.G. "Limnologia e gerenciamento integrado de recursos hídricos. Avanços conceituais e metodológicos. Ciência e Ambiente 21. 9-20 pp. 2001.

VIANNA, Regina Cecere; VIANNA JUNIOR, Claudio Cecere; VIANNA, Rafael Marques. Os recursos de água doce no mundo - situação, normatização e perspectiva. In: Âmbito Jurídico, Rio Grande, VIII, n. 23, out 2005.

ZOBY, J. L. G. \& MATOS, B. Águas subterrâneas no Brasil e sua inserção na Política Nacional de Recursos Hídricos. In: Congresso Brasileiro de Águas Subterrâneas, 12., 2002, Florianópolis-SC. Anais.... Florianópolis: ABAS, 2002. CDROM. 